\title{
Data Deduplication on Encrypted Big Data in Cloud
}

\author{
V. Khanaa, A. Kumaravel, A. Rama
}

\begin{abstract}
Data de-duplication is a standout amongst the most explicit coagulation strategy for dispensing with indistinguishable duplicates of improved information in distributed storage to Defeat the measurement of the storage space and the recovery of the transmission ability. Information pressure performs coherent decrease of storage room by least hashing. To ensure the classification of delicate information while supporting de-duplication, the merged encryption procedure has been proposed to encode the information before re-appropriating. To more readily ensure information security, it endeavors to formally address the issue of approved information de-duplication. Not quite the same as customary de-duplication, the benefits of client improved by upgrading their capacity limit and security examination it likewise present a few new de-duplication developments supporting approved copy check in crossover cloud design. Security examination shows that are set up to keep away from unapproved get to. As proof of notion, we are updating the model of our proposed approved copy control system. and lead proving ground tests utilizing our model. We demonstrate that our proposed approved copy check conspire brings about negligible overhead contrasted with ordinary operations. Deduplication has demonstrated to accomplish high space and cost investment funds and many distributed storage suppliers are presently embracing it. Deduplication can diminish capacity needs by up to 90-95 percent for reinforcement.
\end{abstract}

Keywords: Cloud Computing, Data Deduplication, Minimum Hashing, Encryption, Decryption, Secure Data.

\section{INTRODUCTION}

his Cloud computing is a model for empowering ubiquitous, useful, on-demand access to a prevalent pool. configurable processing assets (e.g., systems, servers, stockpiling, applications and administrations) that can be quickly provisioned and discharged with insignificant administration exertion or specialist co-op cooperation. The definition records five basic attributes of distributed computing: on-request self-administration, wide system get to, asset pooling, fast versatility or development, and estimated administration. It likewise records three administration models (programming, stage and foundation), and four sending models (private, network, open and cross breed) that Collectively sort approaches to cloud leadership. It is suggested that the definition be used as a method for the broad cloud administration of correlations and arrangement procedures, and to give a gauge to talk based on what is

Revised Manuscript Received on August 22, 2019.

V.Khanaa, Department of Information Technology, Bharath Institute of Higher Education and Research, Chennai, Tamilnadu, India.

A. Kumaravel, Department of Information Technology, Bharath Institute of Higher Education and Research, Chennai, Tamilnadu, India.

A. Rama, Department of Information Technology, Bharath Institute of Higher Education and Research, Chennai, Tamilnadu, India. distributed computing to how to best utilize distributed computing [1-8].

Distributed computing appears to give customers unlimited virtualized assets as administrations across the Internet, while concealing phase and utilization subtleties. The present cloud specialist organizations offer both profoundly accessible capacity and hugely parallel figuring assets at moderately low expenses. As distributed computing is common, an increasing measure of information is being discarded in the cloud and shared by clients with defined benefits that characterize the access privileges of the discarded information. The administration of the steadily increasing quantity of data is one of the fundamental tests of distributed storage administrations .To make information the board adaptable in distributed computing,

De-duplication has been an outstanding strategy and has pulled in increasingly more consideration [9-13].

Information de-duplication has numerous structures. Distinctive associations may utilize various de-duplication techniques. It is exceptionally basic to comprehend the reinforcement and reinforcement challenges, while choosing de-duplication as an answer. Information de-duplication has three sorts. Pressure, utilized regularly for long time. Of late, single-example stockpiling has empowered the expulsion of repetitive documents from capacity, for example, files. Most as of late, it is plainly observed the presentation of sub-record de-duplication.

Information pressure does not perceive or kill copy record it simply pack the given document by decreasing the extent of records. Information comp1ression works inside a document to recognize and expel void space that shows up as tedious examples. That de-duplication is neighborhood to the record and stays autonomous of different documents and information portions inside those records. Advantages of Data pressure are constrained however it has been accessible for a long time, it ends up secluded to every specific document. For instance, information pressure can't recognize and evacuate copy documents, however will freely pack every one of the records.

Single-Instance Storage expels various duplicates of any document. Single-example stockpiling (SIS) situations can recognize and dispose of repetitive duplicates of indistinguishable records. As name proposes it keeps just single Instance or duplicate of information and pointers are made for every other client who possess a similar record.

In Single-case stockpiling frameworks, substance of records are checked to decide whether the document to be transferred on cloud is indistinguishable to a current document or not. The quantity of records that are put away as one of 
a kind at cloud, based on document content in Single Instance framework, there might be extensive measure of repetition in that document or records [14-19].

In the event that excess information exists in independent records not should have been indistinguishable documents, that repetition can be maintained a strategic distance from with the assistance of Sub-document Deduplication. Sub-document de-duplication distinguishes repetitive information inside and crosswise over records which isn't the situation in SIS executions. Utilizing sub-record de-duplication, excess duplicates of information are found and are expelled even after the copied information exist, inside non indistinguishable documents. Thus, sub-record de-duplication wipes out the capacity of copy information over an association. In spite of the fact that documents are not indistinguishable, Sub-record de-duplication execution has two sorts. Fixed-length sub-record de-duplication utilizes fixed length of information to scan for the copy information inside the documents. Fixed-length portions are straightforward in configuration, however pass up on numerous chances to find excess sub-record information. For instance, when name of individual is added to specific documents tile page the entire substance of the record will move, coming about the disappointment of the de-duplication to distinguish equivalencies .Means, little change or option in document may cause non equivalencies. Variable-length usage are typically not comparing to fragment length. Variable-length usage coordinate information section sizes to the normally happening duplication inside records, unfathomably expanding the general de-duplication proportion (In the model above, factor length de-duplication will get every single copy portion in the archive, happen in the report [20-22]

\section{ALGORITHM SPECIFICATION}

The short calculation of our whole framework can be depicted as beneath,

Key Generation:

Step 1: Choose two unmistakable $\mathrm{P}$ and q prime numbers.

Stage 2: Find $n$ with an end goal that is $n=p q . ~ N$ will be used as a module for both personal and individual keys.

Step 3: discover the complete value of $n,(n)(n)=(p-1)(q-1)$. Stage 4: Choose an e to the extent that $1_{i} \mathrm{e}$ ! (n) and with the final objective that e and (n) do not share any divisors other More than 1 (e and (n) are usually prime). E is held as an instance of an open key.

Stage 5: Determine d (using a secluded number jongling) that meets the matching link de $=1(\bmod (n))$.

As it were, pick d with the final goal that de-1 may be equally isolated by (p-1) (q-1), the totient, or (n). This is frequently processed using the Extended Euclidean Algorithm, as e and (n) are moderately prime and $\mathrm{d}$ is to be the specific multiplicative inverse of e. D is held as a sort of private key. The open key has the module $\mathrm{n}$ and the individuals in particular (or encryption) type e. The private key has a modulus $\mathrm{n}$ and a private (or decoding) type $\mathrm{d}$, which is still silent.
Encryption: Stage 1: Person A transmits its open key (module $\mathrm{n}$ and instance e) to Person $\mathrm{B}$ while preserving its private key mystery.

Stage 2: When Person B wishes to send a signal "M" to Person A, it first proselytes $M$ to a whole number with the ultimate goal of $0_{i} m_{i} n$ using a reversible convention known as a cushioning system.

Stage 3: Person B registers, with Person The primary data being opened, Figure c comparing to, $\mathrm{c}=\operatorname{me}(\bmod \mathrm{n})$.

Stage 4: Person B currently sends message" in figure content, or $\mathrm{c}$, to Person A.

Decoding:

Stage 1: Person A recovers $\mathrm{m}$ from $\mathrm{c}$ by using the instance of a private key, $\mathrm{d}$, the calculation $\mathrm{m}=\mathrm{cd}(\bmod \mathrm{n})$.

Stage 2: Given m, Person A can recoup the first message" M" by switching the cushioning plan. This methodology works since,

$\mathrm{c}=\operatorname{me}(\bmod \mathrm{n}), \mathrm{cd}=(\operatorname{me}) \mathrm{d}(\bmod \mathrm{n})$ and album $=\operatorname{mde}(\bmod$ $\mathrm{n})$. By the symmetry properties of the mods that we have that $\operatorname{mde}=\operatorname{mde}(\bmod n)$.

\section{SYSTEM IMPLEMENTATION}

Cloud clients transfer individual or private information to the server farm of a Cloud Service Provider (CSP) and enable it to keep up these information. Since interruptions and assaults towards delicate information at CSP are not avoidable it is judicious to accept that CSP can't be completely trusted by cloud clients. Additionally, the loss of command over their very own information prompts high information security dangers, particularly information protection spillages. Because of the quick improvement of information mining and different investigation advances, the security issue ends up genuine. Thus, a great practice is to just re-appropriate scrambled information to the cloud so as to guarantee information security and client protection. Deduplication has demonstrated to accomplish high space and cost reserve funds and many distributed storage suppliers are as of now receiving it. Deduplication can diminish capacity needs by up to $90-95$ percent for reinforcement applications and up to 68 percent in standard document frameworks. Alongside low proprietorship expenses and adaptability, clients require the insurance of their information and secrecy ensures through encryption. Shockingly, deduplication and encryption are two clashing advancements [23-25].

\section{USER MODULE}

Users have authentication and safety in this module to access the details described in the ontology scheme. The customer should have an account in that account before accessing or searching the information. otherwise they should register first.

At the very least, you need to provide an email address, username, password, display name, and whatever The profile areas you have set to be needed. The name of the screen will be used when the system requires to show the 
user's proper name [26-28].

\section{UPLOAD FILE}

The user can start up the server after cloud environment is opened. Then the user login the cloud using the user name and password.

Upload the required document using minimum hashing algorithm, and it will be securely available for cloud users.

\section{UPLOAD FILE}

The user can start up the server after cloud environment is opened. Then the user login the cloud using the user name and password.

Upload the required document using minimum hashing algorithm, and it will be securely available for cloud users.

\section{SECURE DE DUPLICATION SYSTEM}

The tag of record $\mathrm{F}$ will be governed by document $\mathrm{F}$ and the advantage to assist the approved decoupling. We call the record token to show the difference with the usual tag documentation. To assist the approved access to the KP Mystery Key, the benefit $\mathrm{p}$ will be restricted to the production of the Token document.

De-duplication misuses an indistinguishable substance, while encryption seeks to create all substances appear irregular; a comparable substance encoded with two unique keys outcomes in a completely distinct figure content. In this manner, it is difficult to consolidate the space efficiency [29].

\section{LOGIN}

De-duplication misuses an indistinguishable substance, while encryption seeks to create all substances appear irregular; a comparable substance encoded with two unique keys outcomes in a completely distinct figure content. In this manner, it is difficult to consolidate the space efficiency of duplication with the mystery components of encryption [30].

\section{DOWNLOAD FILE}

After distributed storage, the client can download a document that depends on the key or token. When the important request has been received, the sender can either transmit the key or reduce it. The receiver can decrypt the message with this important and application I d produced at the moment of sending the key request.

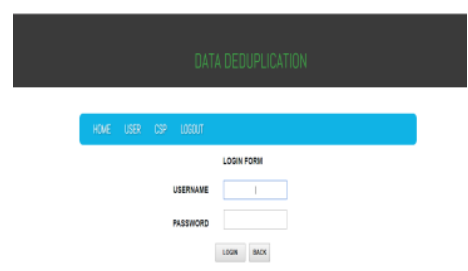

\section{Selection of Process:}
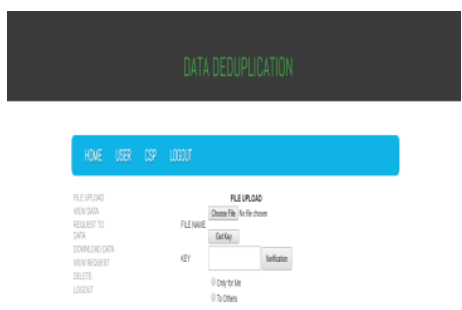

View data:
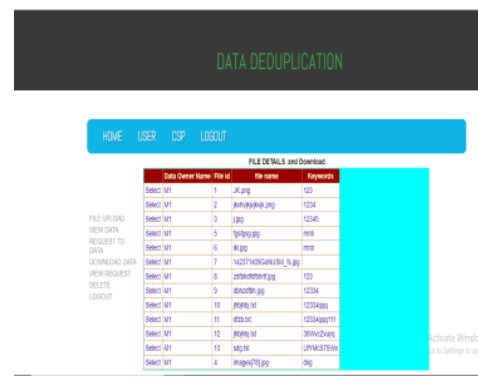

Keyverification:
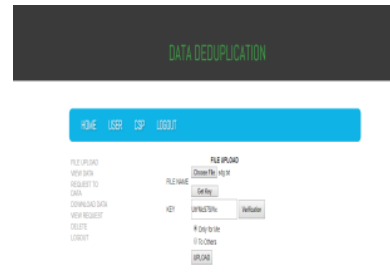

Request Data:
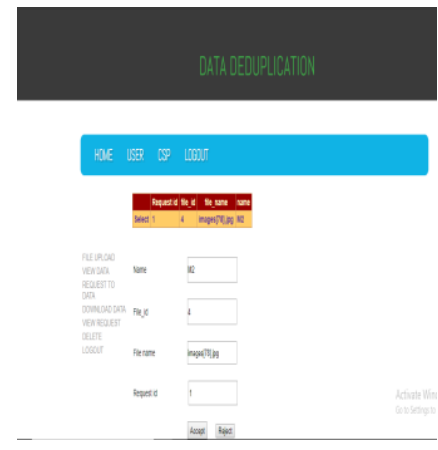

Download Data
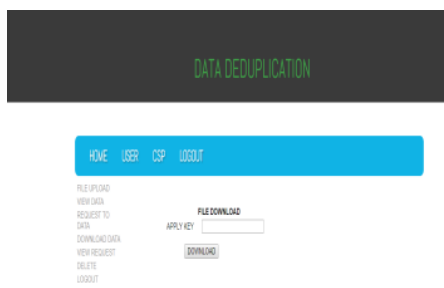


\section{DE-DUPLICATION PROCESS}

The process is as shown in fig1

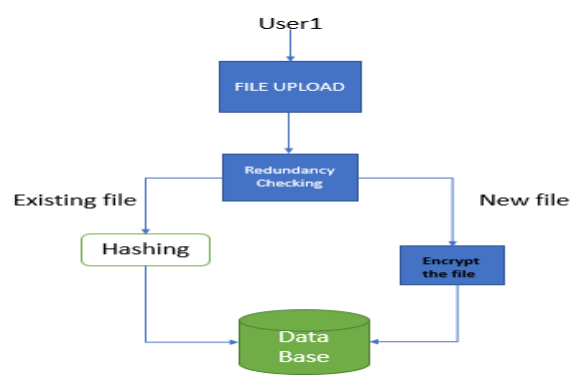

Fig 1. Deduplication

\section{Process}

The tag of document $\mathrm{F}$ will be dictated by the record $\mathrm{F}$ and the advantage to assist the approved decoupling. We call the record token to show the difference with the usual tag documentation. In order to help the approved access to the KP mystery key, the benefit $\mathrm{p}$ will be limited to the production of the record token.

De-duplication misuses an indistinguishable substance, while encryption seeks to create all substances appear irregular; a comparable substance encoded with two unique keys outcomes in a completely distinct figure content. In this way, it is hazardous to consolidate the space skills of duplication with the mysterious components of encryption.

\section{DOWNLOAD FILE}

After cloud storage, the client can download a document that depends on the key or token. When the important request

\section{CONCLUSION}

Authorized de-duplication of data was suggested to guarantee the safety of information by including the differential advantages of customers in the copy checks. It also displays a few copy check tokens of documents generated by a private cloud server with private keys. Security inquiry shows that our plans are safe as far as the insider and untouchable attacks stated in the suggested safety display are concerned. The authorized de-duplication of data shall be granted negligible overhead contrasted with joined encryption and system exchange. Real confinement in current cloud server is information isn't encoded any methods for scrambled strategy. Every one of the information which is put away either open or private cloud is put away in a plain way.

\section{REFERENCES}

[1] Gowri Sankaran, B., Karthik, B. \& Vijayaragavan, S.P. 2019, "Weight ward change region plummeting change for square based image huffman coding", International Journal of Innovative Technology and Exploring Engineering, vol. 8, no. 10, pp. 4313-4316.

[2] Gowri Sankaran, B., Karthik, B. \& Vijayaragavan, S.P. 2019, "Image compression utilizing wavelet transform", International Journal of Innovative Technology and Exploring Engineering, vol. 8, no. 10, pp. 4305-4308.
[3] Kandavel, N. \& Kumaravel, A. 2019, "Offloading computation for efficient energy in mobile cloud computing", International Journal of Innovative Technology and Exploring Engineering, vol. 8, no. 10, pp. 4317-4320.

[4] Vinoth, V.V. \& Kanniga, E. 2019, "Reversible data hiding in encrypting images-an system", International Journal of Engineering and Advanced Technology, vol. 8, no. 6, pp. 3051-3053.

[5] Selvapriya, B. \& Raghu, B. 2019, "Pseudocoloring of medical images: A research", International Journal of Engineering and Advanced Technology, vol. 8, no. 6, pp. 3712-3716.

[6] Senthil Kumar, K. \& Muthukumaravel, A. 2019, "Bi-objective constraint and hybrid optimizer for the test case prioritization", International Journal of Engineering and Advanced Technology, vol. 8, no. 6 , pp. 3436-3448.

[7] Kavitha, G., Priya, N., Anuradha, C. \& Pothumani, S. 2019, "Read-write, peer-to-peer algorithms for the location-identity split", International Journal of Innovative Technology and Exploring Engineering, vol. 8, no. 9 Special Issue 3, pp. 445-447.

[8] Kaliyamurthie, K.P., Michael, G., Anuratha, C. \& Sundaraj, B. 2019 , "Certain improvements in alzheimer disease classification using novel fuzzy c means clustering for image segmentation", International Journal of Innovative Technology and Exploring Engineering, vol. 8, no. 9 Special Issue 3, pp. 599-604.

[9] Kaliyamurthie, K.P., Sundarraj, B., Geo, A.V.A. \& Michael, G. 2019 "RIB: Analysis of I/O automata", International Journal of Innovative Technology and Exploring Engineering, vol. 8, no. 9 Special Issue 3 , pp. 1019-1022.

[10] Velvizhi, R., Rajabhushanam, C. \& Vidhya, S.R.S. 2019, "Opinion mining for travel route recommendation using Social Media Networks (Twitter)", International Journal of Innovative Technology and Exploring Engineering, vol. 8, no. 9 Special Issue 3, pp. 508-512.

[11] Kavitha, R., Sangeetha, S. \& Varghese, A.G. 2019, "Human activity patterns in big data for healthcare applications", International Journal of Innovative Technology and Exploring Engineering, vol. 8, no. 9 Special Issue 3, pp. 1101-1103.

[12] Pothumani, S., Anandam, A.K., Sharma, N. \& Franklin, S. 2019, "Extended VEOT framework - Implemented in a smart boutique", International Journal of Innovative Technology and Exploring Engineering, vol. 8, no. 9 Special Issue 3, pp. 762-767.

[13] Kaliyamurthie, K.P., Michael, G., Krishnan, R.M.V. \& Sundarraj, B. 2019, "Pseudorandom techniques for the internet", International Journal of Innovative Technology and Exploring Engineering, vol. 8, no. 9 Special Issue 3, pp. 915-918.

[14] Aravindasamy, R., Jeffrin Rajan, M., Rama, A. \& Kavitha, P. 2019, "Deep learning provisions in the matlab: Focus on CNN facility", International Journal of Innovative Technology and Exploring Engineering, vol. 8, no. 9 Special Issue 3, pp. 990-994.

[15] Theivasigamani, S., Linda, M. \& Amudha, S. 2019, "Object sensing and its identification \& motion sensing", International Journal of Innovative Technology and Exploring Engineering, vol. 8, no. 9 Special Issue 3, pp. 545-549.

[16] Mary Linda, I., Vimala, D. \& Shanmuga Priya, K. 2019, "A methodology for the emulation of IPv4", International Journal of Innovative Technology and Exploring Engineering, vol. 8, no. 9 Special Issue 3, pp. 848-852.

[17] Velvizhi, R., Priya, D.J., Vimala, D. \& Linda, I.M. 2019, "Increased routing algorithm for mobile adhoc networks", International Journal of Innovative Technology and Exploring Engineering, vol. 8, no. 9 Special Issue 3, pp. 1606-1608.

[18] Sangeetha, S., Anuradha, C. \& Priya, N. 2019, "DNS in real world", International Journal of Innovative Technology and Exploring Engineering, vol. 8, no. 9 Special Issue 3, pp. 937-940.

[19] Geetha, C., Vimala, D. \& Priya, K.S. 2019, "Constructing multi-processors and spreadsheets with SKIVE", International Journal of Innovative Technology and Exploring Engineering, vol. 8, no. 9 Special Issue 3, pp. 516-519.

[20] Yugendhar, K., Sugumar, V. \& Kavitha, P. 2019, "A novel method of univac using fuzzy logic", International Journal of Innovative Technology and Exploring Engineering, vol. 8, no. 9 Special Issue 3, pp. 435-437.

[21] Kaliyamurthie, K.P., Michael, G., Elankavi, R. \& Jijo, S.A. 2019 "Implementing aggregate-key for sharing data in cloud environment using cryptographic encryption", International Journal of Innovative Technology and Exploring Engineering, vol. 8, no. 9 Special Issue 3, pp. 957-959.

[22] Jeffrin Rajan, M., Aravindasamy, R., Kavitha, P.

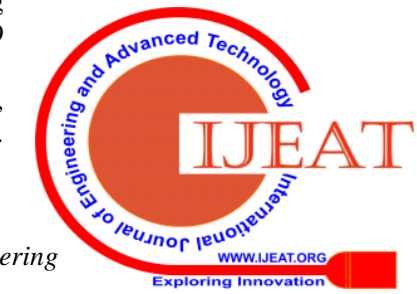


\& Rama, A. 2019, "A novel method of object orientation variation in $\mathrm{C}++$ and java", International Journal of Innovative Technology and Exploring Engineering, vol. 8, no. 9 Special Issue 3, pp. 708-710.

[23] Nayak, R., Dinesh, S. \& Thirunavukkarasu, S. 2019, "A novel method improvement of rapid miner for the data mining applications", International Journal of Innovative Technology and Exploring Engineering, vol. 8, no. 9 Special Issue 3, pp. 457-460.

[24] Sivaraman, K., Krishnan, R.M.V., Sundarraj, B. \& Sri Gowthem, S. 2019, "Network failure detection and diagnosis by analyzing syslog and SNS data: Applying big data analysis to network operations", International Journal of Innovative Technology and Exploring Engineering, vol. 8, no. 9 Special Issue 3, pp. 883-887.

[25] Vimala, D., Linda, I.M. \& Priya, K.S. 2019, "Decoupling online algorithms from erasure coding in DNS", International Journal of Innovative Technology and Exploring Engineering, vol. 8, no. 9 Special Issue 3, pp. 950-953.

[26] Rama, A., Kumaravel, A. \& Nalini, C. 2019, "Preprocessing medical images for classification using deep learning techniques", International Journal of Innovative Technology and Exploring Engineering, vol. 8, no. 9 Special Issue 3, pp. 711-716.

[27] Sangeetha, S., Srividhya, S.R., Anita Davamani, K. \& Amudha, S. 2019, "A procedure for avoid overrun error in universal synchronous asynchronous receiver transmitter (usart) by utilizing dummy join and interrupt latency method", International Journal of Innovative Technology and Exploring Engineering, vol. 8, no. 9 Special Issue 3, pp. 657-660.

[28] Aravindasamy, R., Jeyapriya, D., Sundarajan, B. \& Sangeetha, S. 2019, "Data duplication in cloud for optimal performance and security", International Journal of Innovative Technology and Exploring Engineering, vol. 8, no. 9 Special Issue 3, pp. 1156-1158

[29] Aravindasamy, R., Jeffrin Rajan, M., Sugumar, V. \& Kavitha, P. 2019, "A novel method on developing superblocks and the transistor using apodryal", International Journal of Innovative Technology and Exploring Engineering, vol. 8, no. 9 Special Issue 3, pp. 982-985.

[30] Sasikumar, C.S. \& Kumaravel, A. 2019, "E-learning attributes selection through rough set theory and data mining", International Journal of Innovative Technology and Exploring Engineering, vol. 8, no. 10 , pp. 3920-3924.

\section{AUTHORS PROFILE}

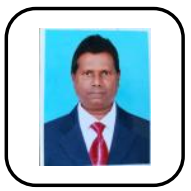

V.Khanaa, Professor, Department of Information Technology, Bharath Institute of Higher Education and Research, Chennai, India

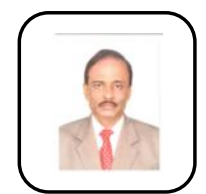

A. Kumaravel Dean, Department of Information Technology, Bharath Institute of Higher Education and Research, Chennai, India

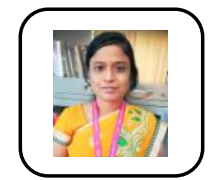

A. Rama, Assistant Professor, Department of Information Technology, Bharath Institute of Higher Education and Research, Chennai, India 